\title{
PROFESSORES DA EDUCAÇÃO BÁSICA NO BRASIL EM TEMPOS DE COVID-19
}

\author{
J. H. BAADE ${ }^{1}$, C. E. GABIEC ${ }^{2}$, F. K. CARNEIRO ${ }^{3}$, S. C. P. MICHELUZZ ${ }^{4}$, P. A. R. MEYER ${ }^{5}$
}

Universidade Alto Vale do Rio do Peixe ${ }^{1}$, Escola Municipal Professora Antonieta Montanari ${ }^{2}$, Escola Municipal Professora Dille Testi Capriglione ${ }^{3}$, Centro de Educação Infantil Mundo Infantil ${ }^{4}$, Instituto Federal Catarinense ${ }^{5}$ baadejoel@gmail.com ${ }^{1}$

\author{
Submetido 07/08/2020 - Aceito 05/11/2020
}

DOI: $10.15628 /$ holos. 2020.10910

\section{RESUMO}

O presente artigo investiga as condições de trabalho remoto e a distância, impostas ao professor da educação básica, devido ao isolamento social decretado em função da Pandemia decorrente da propagação da COVID-19, que é uma doença que tem como principal consequência a insuficiência respiratória grave em um número expressivo de pacientes. A pesquisa se justifica pela abrangência da problemática, os impactos e a necessidade de compreensão desse momento da educação básica na perspectiva dos professores. Assim, a pesquisa permite compreender potencialidades e limites da atuação docente durante a pandemia com vistas ao aperfeiçoamento da sua prática. Metodologicamente, a pesquisa é de natureza aplicada, com objetivo exploratório e descritivo. Utilizou-se como instrumento um questionário estruturado aplicado em formato digital, distribuído conforme a técnica bola de neve, no prazo de dez dias, em que cada respondente era convidado a repassar o questionário a outros sujeitos que exerciam a docência na educação básica. Obtiveram-se 272 respostas de professores que atuam na educação básica, constituindo uma amostra não probabilística. A análise dos dados é quali-quantitativa. Concluiu-se que o isolamento social afetou expressivamente a vida pessoal e profissional dos professores. A intensificação da vida familiar mostrou-se um fenômeno ambíguo. A vida profissional também foi drasticamente afetada, levando à necessidade de se conhecerem novas ferramentas $e$ modos de desempenhar a função, demandando mais tempo e esforço. O exercício das atividades profissionais em casa ainda levou ao esmaecimento das fronteiras entre uma esfera e outra.

PALAVRAS-CHAVE: Pandemia, Isolamento social, Educação, Tecnologias digitais, Aula remota, Professores.

\section{BASIC EDUCATION TEACHERS IN COVID-19 TIMES}

\begin{abstract}
This article investigates the conditions of remote and distance work, imposed on basic education teachers, due to the social isolation decreed due to the Pandemic resulting from the spread of COVID-19, which is a virus whose main consequence is severe respiratory failure in an expressive number of patients. The research is justified by the extent of the problem, the impacts and the need to understand this moment of basic education from the perspective of teachers. Thus, the research allows to understand the potential and limits of teaching performance during the pandemic with a view to improving its practice. Methodologically, the research is of an applied nature, with an exploratory and descriptive objective. A structured questionnaire applied in digital format was used as an instrument, distributed according
\end{abstract}

to the snowball technique, within ten days, in which each respondent was invited to pass on the questionnaire to other subjects who practiced teaching in basic education. 272 responses were obtained from teachers working in basic education, constituting a non-probabilistic sample. Data analysis is quali-quantitative. Social isolation significantly affected teachers' personal and professional lives. The intensification of family life proved to be an ambiguous phenomenon. Professional life has also been drastically affected, leading to the need to learn new tools and ways to perform the job, requiring more time and effort. The exercise of professional activities at home also led to the blurring of boundaries between one sphere and another.

KEYWORDS: Pandemic, Social Isolation, Education, Digital Technologies, Remote Class, Teachers. 


\section{INTRODUÇÃO}

O surto de Coronavírus foi declarado pela OMS - Organização Mundial da Saúde - no dia 30 de janeiro de 2020. O coronavírus se enquadra em doenças com uma transmissibilidade alta, pois, em pouco tempo, desde seu surgimento na província de Hubei, na China, propagou-se rapidamente para praticamente todo o mundo, passando de uma grave epidemia para uma pandemia. No Brasil, os primeiros casos da doença foram registrados no final de janeiro, porém de forma isolada. O vírus passou a ter uma circulação maior no país, em meados de março de 2020.

Segundo o Ministério da Saúde, a "COVID 19 é uma doença causada pelo coronavírus SARSCOV-2, que apresenta um quadro clínico que varia de infecções assintomáticas a quadros respiratórios mais graves" (BRASIL, 2020e). A COVID-19 pode ser assintomática em $80 \%$ dos casos, porém, em $20 \%$, a doença é mais severa e pode levar o paciente a precisar de atendimento hospitalar, pois podem haver complicações que levam ao óbito. O isolamento social é visto como a medida mais eficaz para a prevenção, considerando a inexistência de protocolos de tratamento e vacinas cientificamente comprovados.

Com o aumento rápido de casos, ocorreram os primeiros decretos de isolamento social, pelos governos estaduais, que tiveram autonomia para aplicar regras específicas. Os decretos de isolamento social levaram à interrupção das aulas presenciais em todos os níveis de ensino a partir do dia 15 de março de 2020, em todo o território brasileiro.

Para os professores, essa mudança foi radical em sua vida pessoal e profissional, pois o trabalho passou a ser feito em casa. Nas primeiras semanas, a "casa", que antes significava privacidade, descanso e lazer, perdeu esses sentidos e passou a ser sinônimo de trabalho. 0 professor teve de se reinventar, para dar conta dos compromissos profissionais, do trabalho doméstico e da educação dos filhos. Neste mesmo espaço, precisou buscar lazer e descanso, como forma de manter a saúde física e mental.

Além da conciliação da vida pessoal e profissional em um mesmo espaço físico, o professor precisou se adaptar às tecnologias digitais, antes utilizadas em sala de aula de forma mais esporádica. $O$ computador e o celular, antes mais utilizados para lazer e comunicação, passaram a ser ferramentas de trabalho. O professor precisou vencer desafios e quebrar paradigmas na utilização das tecnologias digitais para o desenvolvimento do seu trabalho. Mais do que isso, o isolamento social representou para os professores a necessidade de repensar a própria educação. Assim, essa pesquisa teve como objetivo investigar as condições de trabalho remoto e a distância, impostas ao professor da educação básica, devido ao isolamento social decretado em função da Pandemia decorrente da propagação da COVID-19.

O texto está estruturado em três partes fundamentais. Na primeira, apresentam-se os principais referenciais teóricos norteadores da análise, tais como a educação básica tradicional; políticas públicas; tecnologias digitais e virtualização do ensino; e formação e capacitação de professores. Em seguida, apresenta-se a metodologia de coleta e análise de dados. Por fim, apresentam-se os resultados e faz-se as respectivas análises. O texto é encerrado com algumas considerações finais e a lista de referências. 


\section{REFERENCIAL TEÓRICO}

Diariamente recebe-se uma grande carga de notícias de todas as naturezas, gerando, a muitos, indiferença para esses acontecimentos. Em novembro de 2019, não foi diferente, o mundo recebeu a informação de um novo vírus, o coronavírus SARS-COV-2. A principal característica desse vírus é a instalação de um quadro de insuficiência respiratória aguda. A sua origem era a China, porém, nem todos se alarmaram, pois era algo que ocorria do outro lado do mundo.

Assim como as informações circulam em uma velocidade sem precedentes, as pessoas atravessam o mundo por meio de viagens aéreas, a turismo ou a trabalho. $O$ vírus não demorou para chegar aos países europeus e, em janeiro de 2020, também ao Brasil, com a identificação do primeiro caso. Em 11 de março de 2020, a Organização Mundial de Saúde (OMS) declarou o estado de pandemia. Em decorrência disso, Estados ao redor do mundo começaram a adotar medidas de isolamento social como forma de prevenção à disseminação do vírus, com o fechamento das atividades produtivas e os setores de serviços, entre eles, todo o sistema educacional.

Anteriormente ao isolamento social, a educação básica era caracterizada pelo ensino convencional, tradicional, no qual o professor transmitia o conhecimento que possui, através de aulas expositivas, para seus alunos. Segundo a Lei de Diretrizes e Bases da Educação (LDB, 1996), o Ensino Fundamental deverá ser presencial.

A partir do surgimento de novas tecnologias que permitem o aprimoramento por meio da educação a distância (ensino não presencial), o termo de ensino presencial começou a ser bastante utilizado. Assim, ainda de acordo com a LDB (1996), a educação a distância, na educação básica, deve ser utilizada apenas em situações especiais. A possibilidade de estudar a distância seria oferecida em dois casos: como complementação da aprendizagem (enriquecimento e aprofundamento do currículo, recuperação e aceleração de estudos para alunos com atraso escolar, dentre outras) e em situações emergenciais.

Anteriormente à pandemia do SARS-COV-2, as situações previstas para uso de recursos de educação a distância na educação básica eram pontuais e localizadas, pois não há registros de utilização em larga escala. O impedimento de aulas presenciais em todo o território brasileiro gerou uma situação sem precedentes, não havendo prescrições e tampouco políticas educacionais que dessem conta das novas demandas.

Com a instauração de decretos de isolamento social em todos os estados da federação, houve a necessidade de adequação para a nova realidade até então esporádica e descontextualizada. O Parecer no 5 de 2020, do Conselho Nacional de Educação (CNE), apresentou a reorganização do Calendário Escolar e a possibilidade de cômputo de atividades não presenciais para fins de cumprimento da carga horária mínima anual (BRASIL, 2020b).

No dia 17 de março de 2020, por meio da Portaria no 343, o Ministério da Educação (MEC) se manifestou sobre a substituição das aulas presenciais por aulas em meios digitais, enquanto durar a situação de pandemia da COVID-19, para instituição de educação superior integrantes do sistema federal de ensino. Essas aulas foram chamadas de ensino remoto. Posteriormente, a Portaria no 343 recebeu ajustes e acréscimos por meio das Portarias no 345, de 19 de março de 2020 (BRASIL, 2020c), e no 356, de 20 de março de 2020 (BRASIL, 2020d). 
De acordo com a LDB (1996), na educação básica, cabe o cumprimento de 800 horas de efetivo trabalho escolar. Em decorrência da suspensão de atendimento escolar presencial, também apresenta em seu art. 24, inciso I - as Instituições de Ensino deverão reorganizar seus calendários com atividades de revisão (Redação dada pela Lei no 13.415, de 2017) (BRASIL, 2017).

Este cenário levou Conselhos Estaduais de Educação de diversos estados e vários Conselhos Municipais de Educação a emitirem resoluções e/ou pareceres orientativos para as instituições de ensino pertencentes aos seus respectivos sistemas sobre a reorganização do calendário escolar e uso de atividades não presenciais, ou seja, Regime Especial de Ensino Remoto. Nesse sentido, as tecnologias digitais passaram a ser demandadas em proporções sem precedentes.

\subsection{Tecnologias Digitais e Virtualização do ensino}

Segundo Chaves (1998), em 1998, as tecnologias digitais já haviam tomado tamanha proporção que a sociedade entraria em colapso caso os computadores deixassem de funcionar. Anos depois, a dependência das tecnologias digitais acentuou-se quando, em 2007, veio o primeiro iPhone para revolucionar a forma como se lida com a tecnologia, causando impactos econômicos e culturais.

Entre as tecnologias digitais, existem diversas nomenclaturas que são utilizadas para determinar sua utilização: Tecnologia da Informação (TI), Tecnologia da Informação e Comunicação (TIC), Tecnologia Digital de Informação e Comunicação (TDIC), Novas Tecnologias de Informação e Comunicação (NTICs), assim como as diferentes evoluções da Internet, utilizando os termos Web 1.0, 2.0, 3.0 e 4.0 .

A Internet é utilizada como o principal meio de transmissão de dados das $\mathrm{TI}$ e, especialmente, das TICs. Ela passou por diferentes fases, sendo a primeira chamada de Web 1.0, na qual a Internet era basicamente unidirecional e o usuário era apenas um consumidor de informação.

Logo em seguida, surgiu a Web 2.0 devido a mudanças no comportamento e necessidade dos usuários. Serviços foram implementados e o usuário tornou-se também criador de conteúdo, foi quando ocorreu a expansão de serviços como as redes sociais, nas quais é possível que o conteúdo seja gerado exclusivamente pelos usuários, sendo a Internet apenas uma plataforma (VAZ, 2015).

A Web 3.0, ou Internet inteligente, se caracteriza como sendo personalizada, onde tanto o conteúdo como principalmente a publicidade é mostrada ao usuário com base no seu histórico (Vaz, 2015). Uma característica da Web 3.0 são as chamadas bolhas sociais, que é quando o conteúdo apresentado é tão específico à demanda dos usuários, que estes têm a impressão de que tudo e todos concordam com suas ideias (SOUZA, 2017). Fala-se, já na internet 4.0, caracterizada pelo emprego de inteligência artificial.

Quanto ao equipamento utilizado para acesso à informação e à comunicação, com a popularização dos smartphones (celulares inteligentes), as informações estão literalmente na palma da mão por meio do acesso à Internet (IPE, 2019). Com equipamentos cada vez mais acessíveis, a sociedade passou e ainda passa por uma revolução na comunicação, segundo a qual as informações dão a volta no mundo em questão de segundos, sendo a Internet o centro dessa 
revolução na comunicação mundial, modificando comunidades e relações sociais (RECUERO, 2000).

\subsection{Formação e capacitação de professores}

Assim como em outros campos, a educação está em constante transformação. Em decorrência disso, para o professor, já não basta a graduação, pois, assim como a sociedade, os alunos pedem e precisam de experiências mais alinhadas às vivenciadas fora do contexto escolar. Explicar a necessidade de mudança e de transformação pela qual passa o ensino atual, implica entender que:

As instituições escolares vêm sendo pressionadas a repensar seu papel diante das transformações que caracterizam o acelerado processo de integração e reestruturação capitalista mundial. De fato, [...] essas transformações [...] decorrem da conjugação de um conjunto de acontecimentos e processos que acabam por caracterizar novas realidades sociais, políticas, econômicas, culturais, geográficas (LIBÂNEO, 2004, p. 45).

Ainda segundo Libâneo (2004), dentre os aspectos mais visíveis desse fenômeno, destacam-se: avanços tecnológicos, a globalização da sociedade, a difusão da informação, o agravamento da exclusão social, entre outros fatores. Diante de tamanha complexidade, questiona-se: quem deterá tal conhecimento a ponto de instrumentar o cidadão que irá exercer tais habilidades/competências? Como encontrar um profissional que corresponda aos perfis socialmente estabelecidos pelas exigências sociais?

Concebendo a escola como espaço apropriado para prover o cidadão das bases de conhecimento para uma vida em sociedade, urge repensar a atuação de um professor preparado teórica e praticamente, de modo a ministrar um ensino para a transformação. No entanto, salientase que a transformação social não é encargo apenas da escola, todavia, ela é um dos caminhos mais propícios para isso.

Nesse contexto, a formação continuada encontra o seu espaço nas necessidades pedagógicas, visto que, conforme afirma Libâneo (1998, p. 227):

[...] a formação continuada pode possibilitar a reflexividade e a mudança nas práticas docentes, ajudando os professores a tomarem consciência das suas dificuldades, compreendendo-as e elaborando formas de enfrentá-las. De fato, não basta saber sobre as dificuldades da profissão, é preciso refletir sobre elas e buscar soluções, de preferência, mediante ações coletivas.

Diante disso, pode-se observar que, nas sociedades contemporâneas, há algum tempo, encontram-se exemplos de formação continuada, ora como maneira de preencher lacunas deixadas pelo sistema escolar, ora como uma atividade fundamental para o desenvolvimento do indivíduo e da sociedade (DESTRO, 1999, p. 19).

No que se refere à conceituação de educação continuada, Destro $(1999$, p. 25) define: “[...] educação continuada é toda e qualquer atividade que possibilite provocar mudanças de atitudes e comportamentos, a partir da aquisição de novos conhecimentos, conceitos e atitudes".

A educação continuada é destacada na LDB, em seu artigo 67, inciso II, dispondo que os planos de carreira devem assegurar aperfeiçoamento profissional continuado e aponta como 
finalidade dos institutos superiores de educação, a oferta de programas de educação continuada para profissionais da educação (BRASIL, 2017).

Martins (1999, p. 132) acentua que cada sistema de ensino elabore os próprios programas permanentes de desenvolvimento profissional do magistério, com cursos, atividades e recursos definidos pelos órgãos responsáveis pela educação. Uma alternativa, embora dispendiosa, é a parceria com outras instituições ou empresas, no âmbito de instituir centros de formação e desenvolvimento profissional do magistério, objetivando, assim, a melhoria da qualificação do magistério associado a uma educação de qualidade.

Para que a formação continuada possa surtir resultados positivos, torna-se fundamental que o profissional se conscientize de que sua ação atualizada favorece o processo no desenvolvimento, tanto no contexto atual, quanto numa perspectiva de futuro, afirma Buarque (2003).

Na visão de Nóvoa (2002, p. 18), "Só o profissional pode ser responsável por sua formação e o desafio deste, é manter-se atualizado sobre as novas metodologias de ensino e desenvolver práticas pedagógicas eficientes". Cabe ao professor conscientizar-se de que a formação continuada não é moda passageira. Prado (2003, p. 47) enfatiza que essa reflete o mundo cada vez mais veloz em que se vive, que se renova a cada instante. Conforme o autor, a escola mudou e os alunos também. Portanto, cabe ao professor seguir o mesmo caminho.

Nesse contexto, cabe referência ao conceito de "arquiteto cognitivo" de Ramal (2002), referido por Lévy (2005) e por Silva, Souza e Carmo (2016). Entre as principais características desse profissional, está a preocupação com o próprio aperfeiçoamento com vistas a uma prática pedagógica mais eficaz. Ele é também capaz de delinear estratégias e trajetórias que levarão o aluno a empreender e traçar o próprio caminho de aprendizado. $O$ arquiteto cognitivo sistematicamente reavalia a sua própria atuação, numa perspectiva de práxis educativa e contextualizada. Recursos e tecnologias não são um fim para ele, mas meios dos quais se apropria criticamente.

\section{METODOLOGIA}

Esta é uma pesquisa de natureza aplicada e quali-quantitativa. Quanto aos objetivos, ela pode ser classificada como descritiva e exploratória, pois se ocupa com a análise de perfil e práticas docentes durante o período de pandemia da COVID-19. Quanto aos procedimentos técnicos, pode ser classificada como de levantamento.

$O$ instrumento de coleta de dados consistiu-se de um questionário estruturado com questões abertas e fechadas, aplicado em formato digital a docentes atuantes na educação básica. A primeira seção do questionário abordou questões referentes ao perfil docente, tais como faixa etária, rede e locais de atuação e áreas de formação.

Como o principal objetivo referiu-se aos professores da educação básica em relação à situação de isolamento devido à COVID 19, utilizou-se como parâmetro o antes e depois do isolamento, com questões abertas, de múltipla escolha e de escala linear. As questões constantes nessa seção indagaram sobre: organização das atividades, escala de estresse, relação e tempo destinado à família, relação com a família dos alunos, tempo destinado à organização das aulas, 
uso de tecnologias, capacitações oferecidas para o desenvolvimento de aulas remotas, comunicação com os alunos e seus familiares e quais as percepções positivas e negativas na visão dos participantes.

O questionário para a obtenção de dados, sendo esse método também chamado de Survey, serve para a obtenção de dados, informações, opiniões, ações de pessoas que fazem parte de um determinado grupo. A principal característica desse método é produzir descrição quantitativa de uma população. Esse tipo de método é ideal para se saber: "o quê", "por quê?" "como?" e "quanto?" para assim determinar "o que está acontecendo" e "como está acontecendo".

Os dados obtidos configuram uma amostra aleatória e não probabilística, sendo que não houve controle sobre o número de participantes. O critério de inclusão foi a atuação na educação básica e o aceite para participação na pesquisa, por meio do preenchimento do questionário em formato digital. Não foram coletados dados pessoais que permitissem a identificação dos sujeitos, assegurando o anonimato. Empregou-se a técnica "bola de neve" com amostra exponencial para a aplicação do questionário, em que cada participante era convidado a distribuir o questionário a outros docentes da educação básica, conforme também empregado por Pederneiras et. al. (2011). Nos resultados, cada participante é identificado com a letra " $\mathrm{P}$ ", seguida do identificador único gerado pelo software empregado na coleta.

\section{RESULTADOS E ANÁLISE}

A proposta desta pesquisa direcionou-se aos profissionais da Educação Básica que estão trabalhando de forma diferenciada (trabalho remoto) e em isolamento social devido à pandemia da COVID-19 há aproximadamente dois meses à época de aplicação do questionário.

\subsection{Perfil dos participantes}

A pesquisa foi realizada entre os dias 28 de maio e 07 de junho de 2020 e contou com a participação de 272 profissionais da educação, abrangendo 41 municípios, preponderantemente dos estados do Paraná e Santa Catarina, sendo que o município de maior participação foi União da Vitória, PR, com 35,9\%. Do total dos envolvidos, 90,8\% fazem parte da rede pública, $6,6 \%$ da rede privada e $2,6 \%$ dos respondentes atuam na rede privada e pública simultaneamente.

A imagem 1 apresenta a distribuição geográfica dos respondentes pelo território brasileiro. 


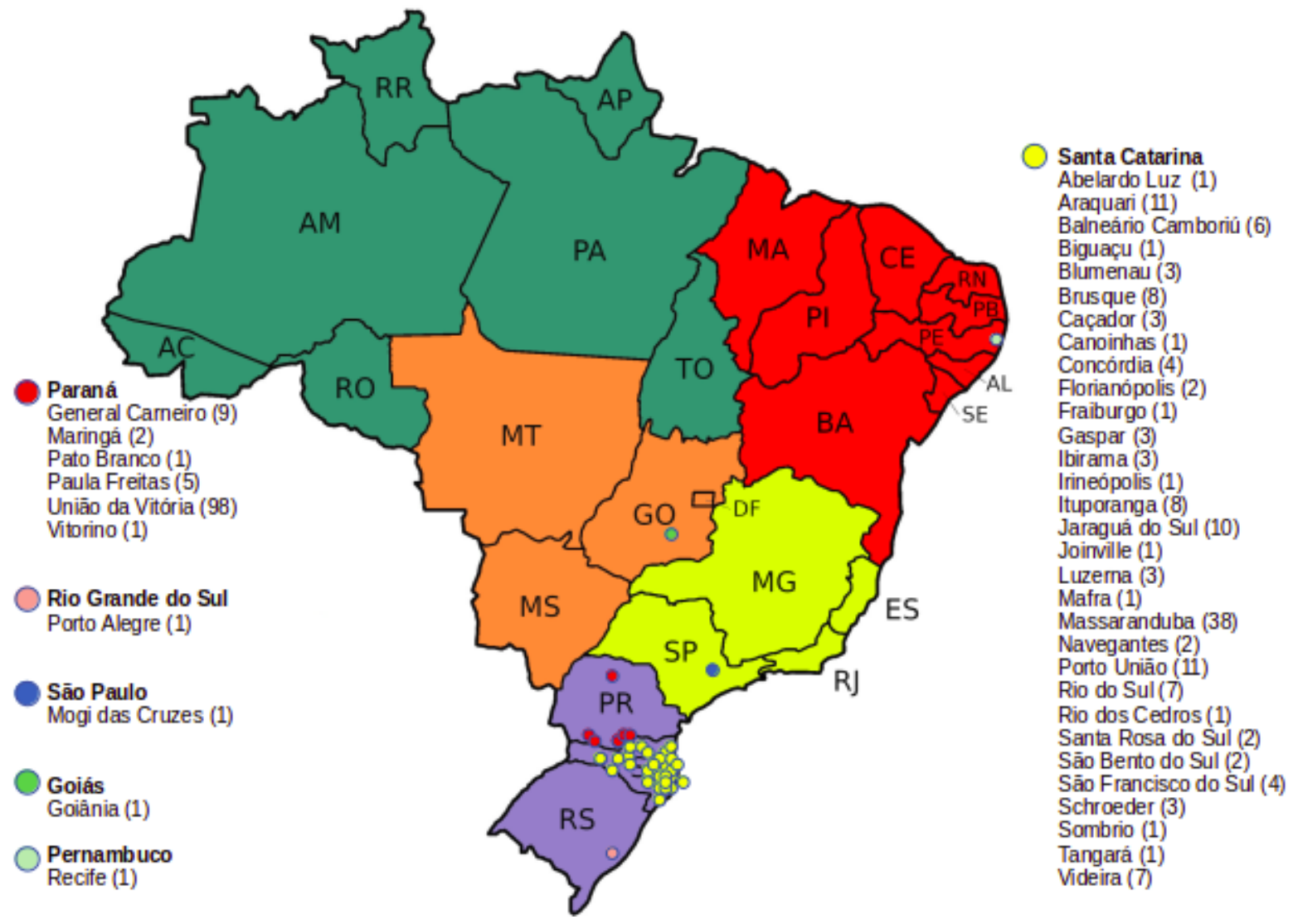

Imagem 1: Distribuição geográfica dos respondentes

A faixa etária predominante dos respondentes é de 36 a 50 anos, com 155 profissionais (56,9\%). O número de profissionais com menos de 36 anos foi de $75(27,5 \%)$ e $42(15,4 \%)$ possuíam mais de 50 anos de idade.

O gráfico 1 apresenta o nível de formação dos participantes da pesquisa.
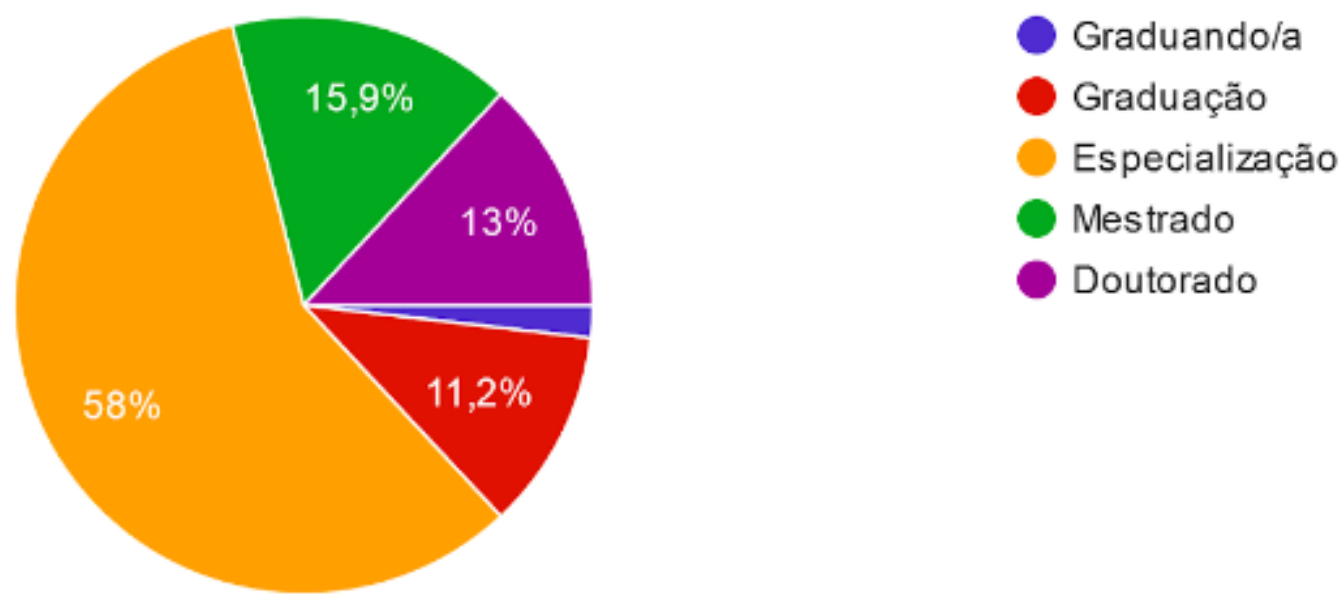

Gráfico 1: Nível de formação dos participantes da pesquisa

A área de formação que se destacou foi Pedagogia, com 49,6\% (137). Do total, 39 (14,3\%) possuem pelo menos uma segunda formação, destacando-se as áreas de letras, matemática, história, geografia, filosofia, artes e química. 
O gráfico 2 apresenta o nível de atuação dos profissionais que responderam à pesquisa, sendo que 68 (25\%) participantes atuam em mais de um nível.

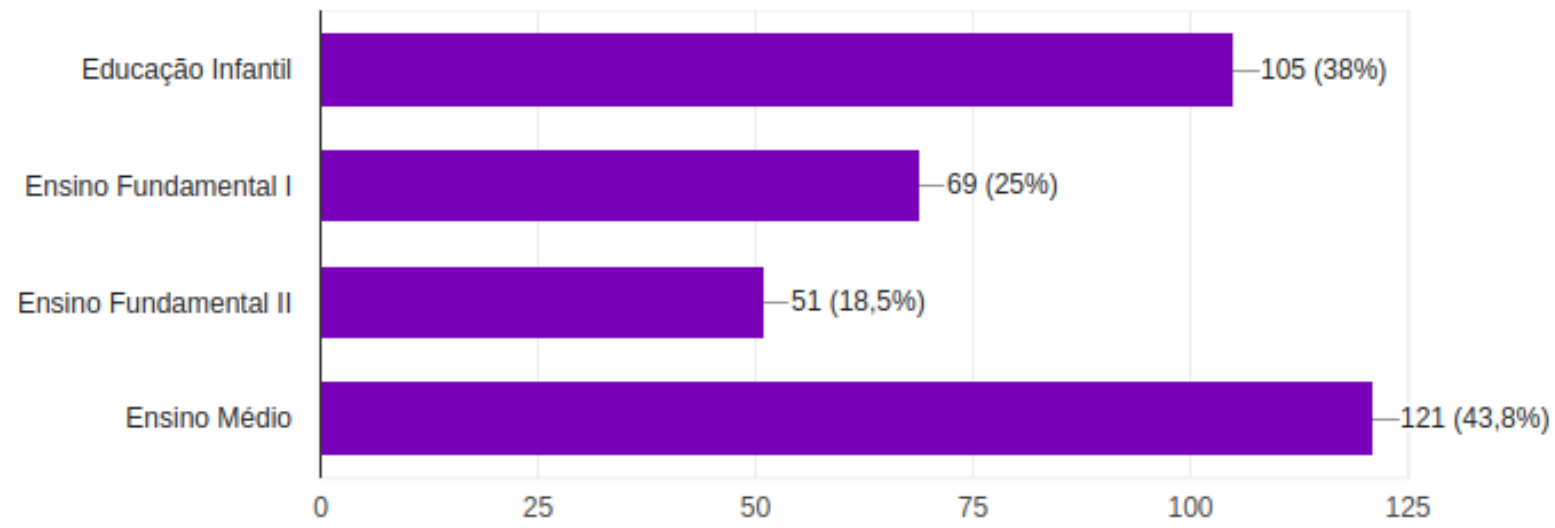

Gráfico 2: Nível de atuação dos respondentes da pesquisa

\subsection{Rotina antes e depois}

As substituições de aulas presenciais por aulas em meios digitais foram autorizadas pela portaria no343 do MEC (BRASIL, 2020a). Dessa forma, as aulas continuaram em todas as redes estaduais mesmo após o fechamento temporário das escolas devido ao isolamento social causado pela pandemia $(G 1,2020)$. Da mesma forma que o governo federal, os estados emitiram resoluções autorizando as aulas não presenciais em suas redes, a exemplo de Santa Catarina, com a resolução CEE/SC no 92020 (SANTA CATARINA, 2020), e do Paraná, com a resolução CEE/CP no 12020 (PARANÁ, 2020).

Com a continuidade das aulas de forma remota, esse estudo buscou saber como a rotina dos professores foi afetada. Questionou-se quanto ao que mais ocupava o tempo no dia a dia antes e depois do isolamento social. Entre os participantes da pesquisa, tanto antes quanto depois dos decretos de fechamento das escolas, a maioria ainda ocupa a maior parte do tempo em função do trabalho, com uma redução de $94 \%$ para $89 \%$. Porém, a maneira como esse trabalho ocorre mudou drasticamente.

Durante as atividades presenciais, a maior parte do tempo era utilizada em função de aulas: preparo, planejamento, desenvolvimento de atividades e a aula propriamente dita. De maneira geral, nas respostas obtidas, a palavra aula está atrelada tanto à preparação quanto ao tempo em sala de aula. Enquanto a palavra atividade, segunda mais citada, está atrelada à correção de trabalhos realizados pelos alunos. No gráfico 3, à esquerda, pode-se visualizar as palavras mais citadas como resposta no questionário referente ao período anterior aos decretos de distanciamento social. 


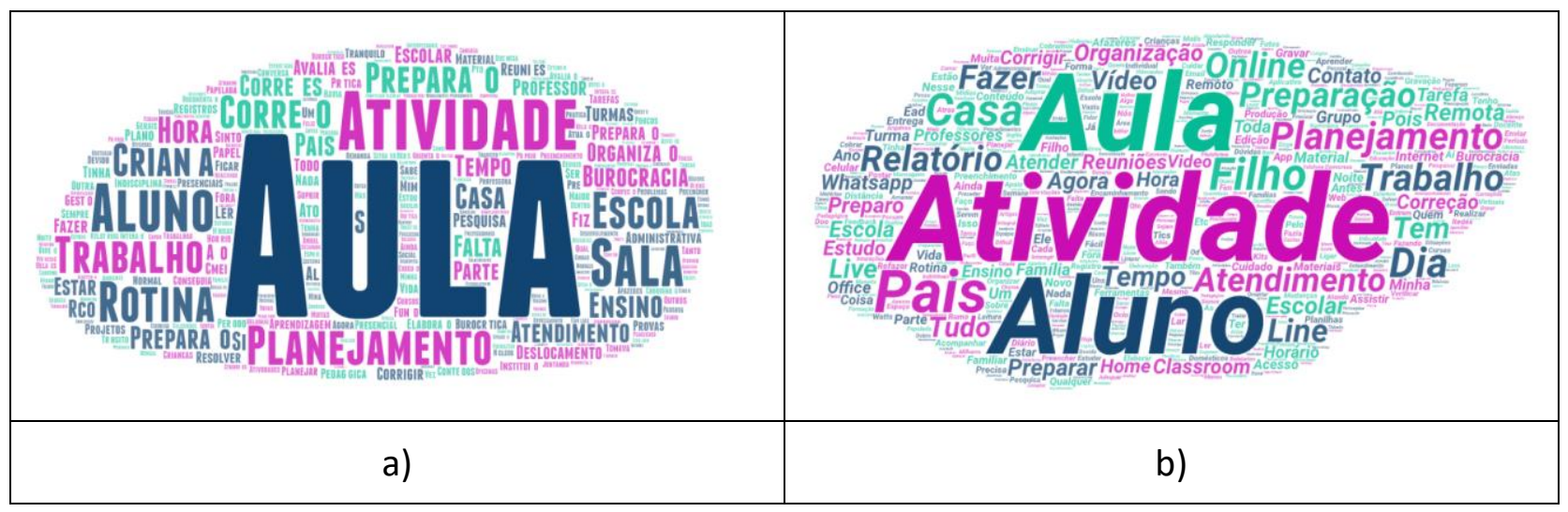

Gráfico 3: Ocupação do tempo - a) antes do isolamento; b) após o isolamento social

Com relação à forma como o tempo passou a ser utilizado depois dos decretos de distanciamento social, as palavras mais citadas podem ser visualizadas no gráfico 3 , à direita. Fica clara a inversão entre as palavras aula e atividade. Isso demonstra como as aulas presenciais foram substituídas, em parte, por atividades enviadas aos alunos para serem realizadas em suas casas.

Nas respostas obtidas sobre o período de distanciamento social, percebe-se o destaque das palavras "aluno" e "pais". Nas respostas em que a palavra "aluno" foi citada, esteve relacionada a atendimento, orientação e cobrança para realização de atividades. Durante as aulas presenciais, "aluno" havia sido citada 25 vezes; enquanto nas aulas remotas, ela aparece 47 vezes. Um aumento significativo também se percebe com relação à palavra "pais", de 4 para 25 vezes, indicando um esforço por parte dos professores para que a comunicação com os alunos se mantivesse, mesmo que em ambiente virtual. Infere-se que os "pais", especialmente nos casos da educação infantil e anos iniciais, tornaram-se mediadores entre a ação do professor e do aluno.

Em outro aspecto, houve um aumento significativo da quantidade de professores que ocupam a maior tempo de seu tempo em atividades relacionadas aos cuidados domésticos (16). Essa resposta não apareceu nenhuma vez antes do fechamento temporário das escolas. Em outro estudo, realizado pelo Instituto Península (2020), 71\% dos professores passaram a dedicar parte do seu tempo a "Organizar a vida Pessoal e Familiar (incluindo questões do lar)".

A pandemia também trouxe outra mudança na rotina dos professores, que diz respeito ao cuidado dos filhos. Antes, apenas um ressaltou esta atividade; já após o isolamento, 19 passaram a dedicar tempo expressivo ao cuidado dos filhos. A exemplo do respondente P75, a maior parte do tempo gasto após os decretos de isolamento social foi em "ser professora de filho". Os professores referiram o seguinte com relação à mudança em suas rotinas:

Tudo! Está tudo um caos. Atendo aluno/pais 24h por dia. Não tem horário p[a]ra nada. Corrijo lições, atendo alunos e pais no whats o tempo todo, preparo aula, cuido da casa, filho de 1 ano, tudo junto, está muito puxado (P211).

Consigo me organizar mais, tenho tempo p[a]ra planejar e tempo para assistir as Lives e formação, e ainda ajudar meus filhos nas atividades (P106).

Percebe-se que a rotina dos professores foi afetada pela pandemia da COVID-19, tanto relacionada ao seu trabalho quanto à sua vida pessoal. Houve nas respostas os dois extremos sobre a mudança na rotina, sendo percebida por uns como boa e, por outros, como ruim. A vivência do 
isolamento pelos profissionais da educação, seja no âmbito pessoal quanto profissional, revelouse, dessa forma, um fenômeno ambíguo e que ainda exigirá mais estudo para melhor compreensão.

\subsection{Relação com família e vida pessoal}

Quanto à relação dos professores com a sua família, a pesquisa mostrou que ela mudou com os decretos que levaram ao isolamento social. Os participantes responderam numa escala de 0 a 10 qual o nível de dedicação à família antes e após o início do isolamento social.

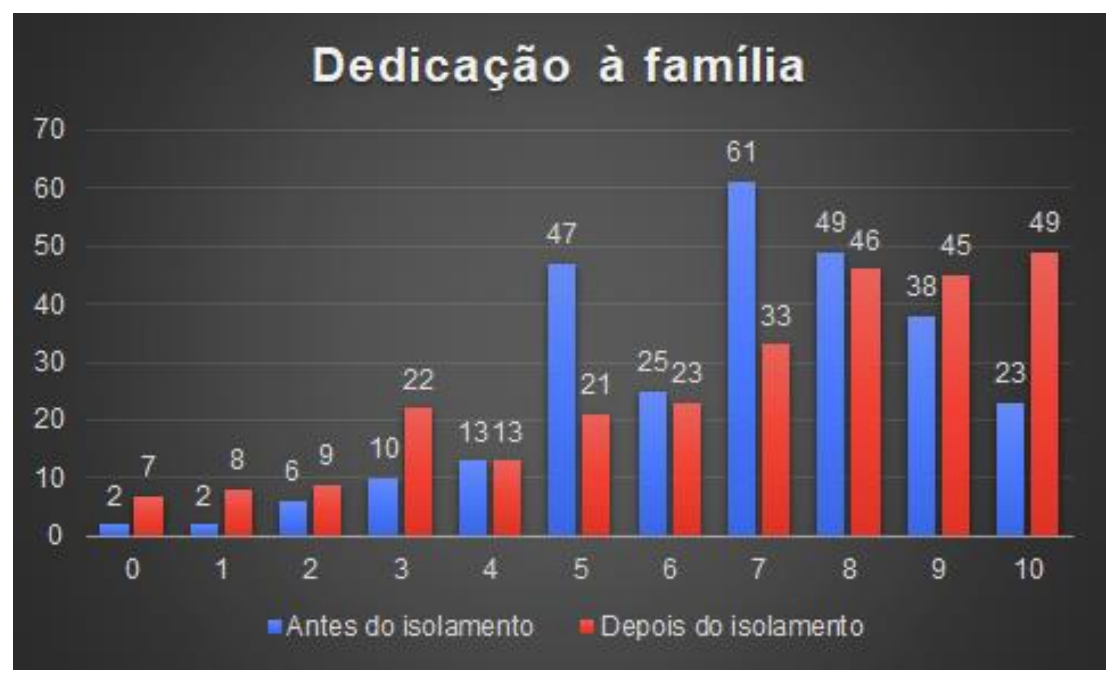

Gráfico 5: Dedicação à família antes e após isolamento social

Percebe-se, em algumas declarações, que o tempo com a família aumentou e teve caráter positivo (38,5\%): "Atenção com os filhos momento de organizar os estudos deles (6 anos) e disposição para brincar (2 e 6 anos) organização diária da casa" (P11). Já para outros, o maior tempo em casa não está sendo considerado de qualidade: "Tenho dedicado mais tempo ao trabalho e esquecido um pouco dos momentos em família" (P12). Percebeu-se também que a maior ou menor possibilidade de dedicação às atividades familiares esteve relacionada à capacidade de organização pessoal do tempo.

A dificuldade maior para a organização do tempo, para 14,6\% dos participantes, esteve relacionada ao aumento do trabalho. Já para $34 \%$, além do aumento do volume de trabalho, a atuação em home office tornou mais difícil a distinção entre atividade profissional e vida pessoal, levando a menor dedicação de tempo à família. Percebe-se isso na fala de P39: "Menos atenção, mesmo em casa".

Outros aspectos relacionados à vida pessoal relatados estiveram vinculados à redução expressiva do convívio e existência social, o aumento de ansiedade e estresse, a redução de atividades físicas e a flexibilidade de horário. A fala de P60 ilustra a nova rotina pessoal:

Necessidade de preparar refeições, de manter a casa mais organizada por ser pequena e não ter um lugar adequado para trabalhar, o que exige montar/desmontar espaços para reuniões e gravações, maior dispêndio de tempo para as rotinas como compras de supermercado, que exigem higienização muito mais rigorosa. 
De modo geral, infere-se que a situação de isolamento social representou uma situação turbulenta na vida, tanto em termos profissionais como pessoais.

\subsection{Tecnologias, capacitação e treinamentos}

O gráfico 6 apresenta o uso de recursos tecnológicos antes e após o início da pandemia.

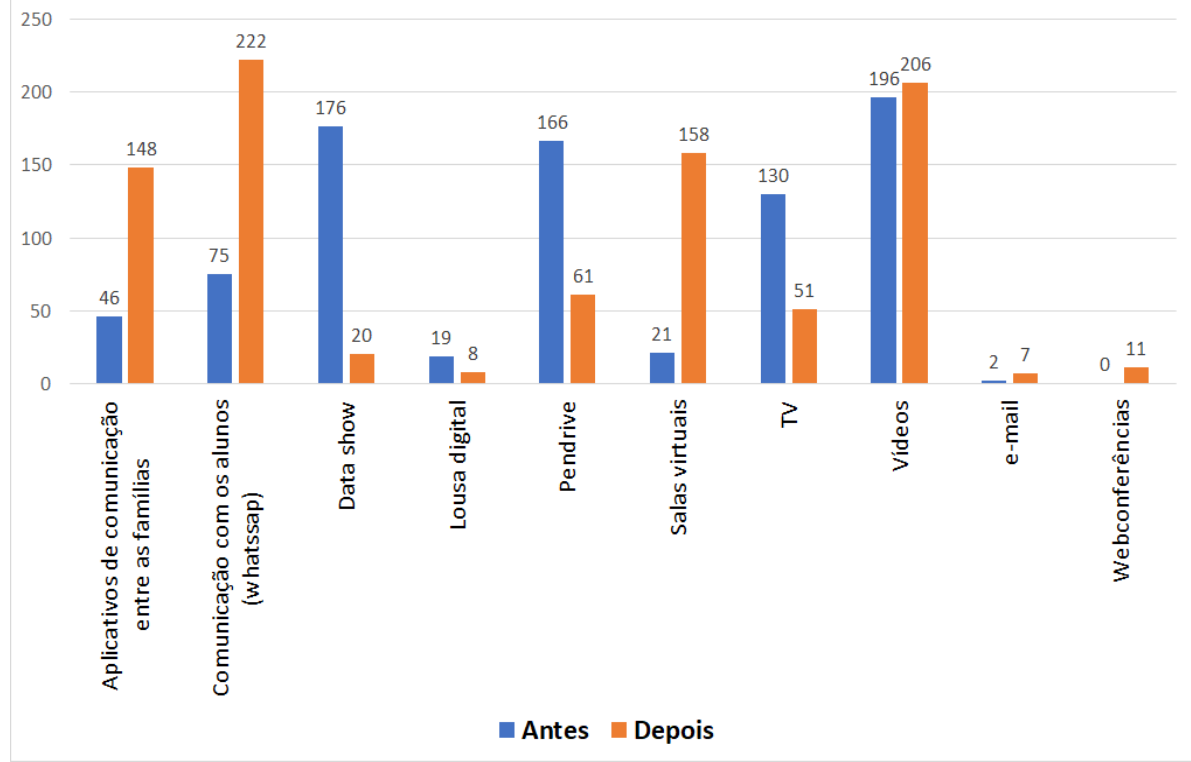

Gráfico 6: Recursos tecnológicos

Conforme o gráfico 6 , percebe-se o aumento do uso de recursos que viabilizassem a comunicação com alunos e família. O uso de tecnologias digitais no período pré-pandemia está também de acordo com a pesquisa de Silva, Souza e Carmo (2016). Destaca-se o uso do WhatsApp, mencionado por $81,6 \%$ dos participantes. $O$ uso de ambientes virtuais também teve incremento expressivo, de $7,7 \%$ para $58 \%$ após o início do isolamento. 0 uso de vídeos se manteve antes e após o isolamento, mas a modalidade de acesso sofreu alteração, sendo que antes eles eram exibidos em sala por meio de aparelho de TV e/ou projetor multimídia (Datashow) da escola e, após, por meio das plataformas de streaming, como Youtube ${ }^{\circledR}$. A redução do uso de pendrive (para transferência dos arquivos), TV e Datashow após a pandemia corrobora isso.

Relacionado à formação e treinamento, $51,4 \%$ dos professores alegam que não tiveram capacitação ou treinamento para desenvolver as suas aulas após os decretos de isolamento. Para os que tiveram treinamento, percebe-se que foram oferecidos através de vídeos disponibilizados na Internet e live (transmissão ao vivo). As formações realizadas foram oferecidas pelo governo estadual, pelas secretarias municipais de educação e também pelas próprias instituições de ensino. Percebe-se aqui uma lacuna entre a disponibilidade de tecnologias digitais e a capacidade de seu uso pelos sujeitos da escola. Silva, Souza e Carmo (2016) recorrem ao termo "arquiteto cognitivo" de Ramal (2002) para expressar o desafio do emprego nas tecnologias digitais na educação, sendo que a sua constituição depende de fatores pessoais, profissionais e infraestruturais. 


\subsection{Estratégias pedagógicas}

Quanto às estratégias pedagógicas, percebem-se duas questões fundamentais: o tempo dedicado ao preparo das aulas; e a questão da aprendizagem. O gráfico 7 apresenta comparativo do tempo dedicado à preparação de aulas antes e após o isolamento social.

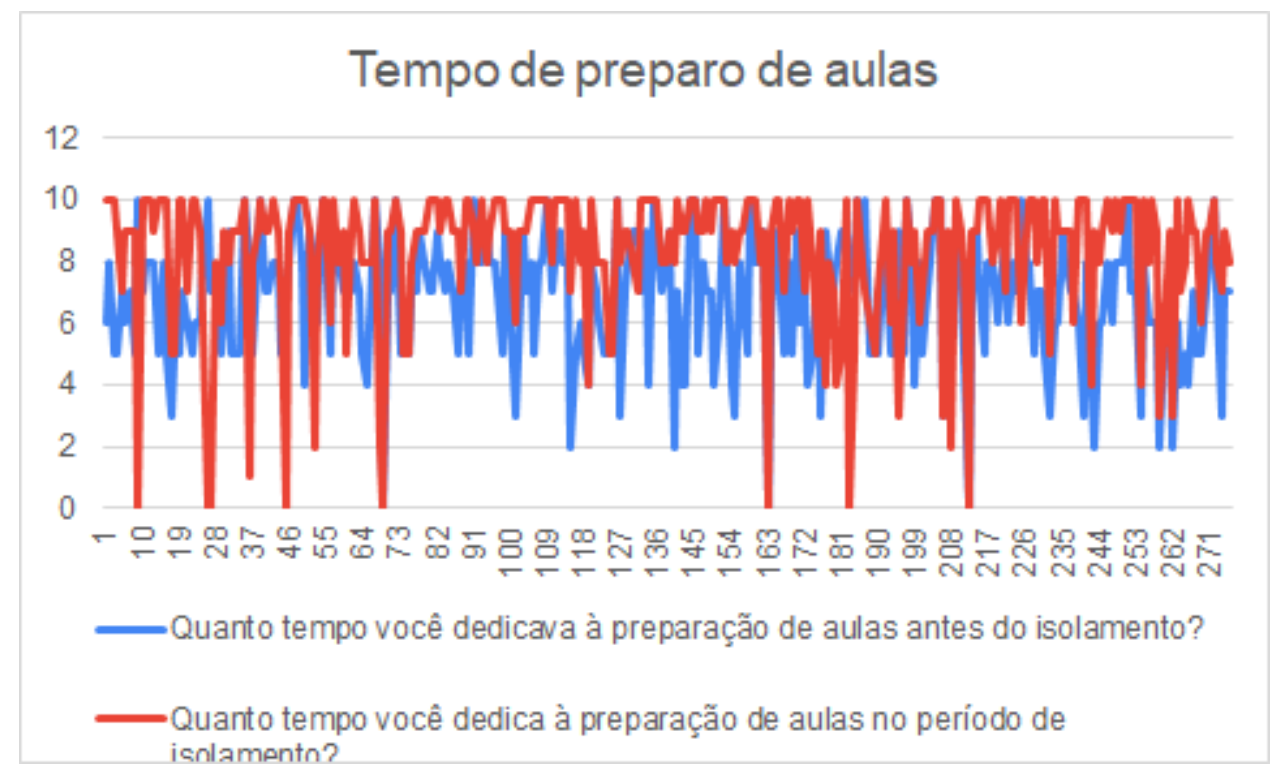

Gráfico 7: Tempo dedicado à preparação de aulas

Conforme o gráfico 7, antes do isolamento social, a dedicação de tempo à preparação de aulas estava concentrada na faixa de 5 a 9 pontos, em uma escala de 0 a 10. Depois, constata-se maior variação de tempo dedicado à preparação, indicando que muitos profissionais $(78,2 \%)$ concentraram energias na busca de adaptação à nova realidade e manutenção de objetivos de aprendizagem, sendo que antes este percentual era de $42,1 \%$.

No que se refere à aprendizagem dos alunos, 61,3\% indicou que ela piorou, 31,2\% consideraram que o isolamento não influenciou o aprendizado e 7,4\% indicou que o aprendizado melhorou. A piora na aprendizagem dos alunos é associada pelos profissionais à dificuldade de interação professor-aluno (37\%), como citado por P09: "Praticamente não há interação entre aluno e professor"; a falta de interesse dos alunos (17\%); a falta de apoio da família (10,35\%); a dificuldade de avaliação (11,6\%); e ainda $11 \%$ consideram as causas multifatoriais, como afirma P153:

Esse tipo de ensino exige do aluno condições materiais de acesso ao material disponibilizado, bem como autonomia no processo de ensino. Ambas as características se mostram pouco presentes, principalmente a primeira. Esse quadro se instala na medida em que os alunos não têm condições materiais que propiciem acesso de qualidade à internet e recursos técnicos para o ensino nessa modalidade. Se instala também nas condições materiais do professor na produção desse material e na demanda por carga horária gerada no processo de produção, uso e avaliação das produções dos alunos.

Para os que afirmaram indiferença na aprendizagem dos alunos, isso se deve mais à brevidade da experiência e à falta de instrumentos de verificação. Isso é bem destacado por P05: 
"Ainda não consegui identificar a diferença do aprendizado. Comecei a aplicar atividades remotas há pouco tempo.".

Ainda $7,4 \%$ dos participantes afirmou que houve melhora na aprendizagem dos alunos. Desses, metade justificou essa melhora à ajuda da família, enquanto os demais associaram essa melhora ao fato de os alunos gostarem de tecnologia, por haver maior liberdade para o aluno se comunicar com o professor, pela maior criatividade das aulas ou ao acesso a mais recursos, como calculadoras e softwares, não presentes em sala de aula convencional.

Nesse sentido, a melhora poderia não ser real, mas apenas aparente. De todo modo, os resultados indicam que os professores ainda não se sentiam adequadamente em condições de avaliar os impactos do isolamento social na qualidade da educação. As percepções indicam a existência de experiência distintas para alunos e professores. Os dados indicam que há alunos com incremento do nível de aprendizado, embora não necessariamente dentro dos moldes curriculares tradicionais. Por outro lado, há indicação também de um número expressivo de crianças para as quais o isolamento social representou a alienação completa da escola e da educação.

\section{CONSIDERAÇÕES FINAIS}

Devido ao surto de Coronavírus SARS-COV-2, à declaração de pandemia pela OMS e aos decretos estaduais de isolamento social em todo o território brasileiro, as aulas presenciais na educação básica foram suspensas e os professores passaram a aplicar atividades remotas. Diante disso, constatou-se a necessidade de analisar os impactos e compreender esse momento da educação básica na perspectiva dos professores. A pesquisa ocorreu em 41 municípios de seis estados brasileiros, abrangendo um total de 272 profissionais da educação. Foram investigados aspectos comparando antes e depois dos decretos de isolamento, como rotina, relação com família e vida pessoal, treinamento e capacitação tecnológica e, finalmente, estratégias pedagógicas.

A pesquisa evidenciou a pluralidade de experiências docentes decorrentes da situação de isolamento social. O mesmo pode ser dito em relação à experiência dos alunos, na visão dos professores. Devido à situação completamente atípica, as "zonas de conforto" dos diferentes sujeitos da educação foram abaladas, demandando grande esforço de adaptação à nova realidade. Isso repercutiu na organização da rotina da vida pessoal, especialmente o relacionamento com a família em casa sofreu grande mudança. A intensificação da vida familiar mostrou-se ainda um fenômeno ambíguo. A vida profissional também foi drasticamente afetada, levando à necessidade de se conhecerem novas ferramentas e modos de desempenhar a função, demandando mais tempo e esforço. $O$ exercício das atividades profissionais em casa ainda levou ao esmaecimento das fronteiras entre uma esfera e outra.

Devido à atualidade da situação retratada, ainda não é possível saber de todas as consequências do isolamento social decorrente da pandemia da COVID-19 para a educação. Assim, o caráter exploratório desse estudo permitiu constatar impactos na vida pessoal e profissional dos professores da educação básica, de modo que novos estudos sobre esses impactos ao longo do tempo são necessários. Serão necessárias, ainda, pesquisas tanto para entendimento dos efeitos, por exemplo, na saúde e qualidade de vida dos profissionais, como as consequências para os sistemas de ensino e a qualidade do aprendizado dos estudantes. Os impactos na vida e nos 
estudos na perspectiva dos estudantes constituem-se outro aspecto fundamental para pesquisas futuras.

\section{REFERÊNCIAS}

Brasil (2017). Lei 9.394/96 de 20 de dezembro de 1996. LDB: Lei de diretrizes e bases da educação nacional. - Brasília: Senado Federal, Coordenação de Edições Técnicas, 2017. 58 p. Disponível em:

http://www2.senado.leg.br/bdsf/bitstream/handle/id/529732/lei de diretrizes e bases 1e d.pdf. Acesso em: 24 jun. 2019.

Brasil (2020a). Ministério da Educação. Portaria no 343, de 17 de Março de 2020. Disponível em: http://www.in.gov.br/en/web/dou/-/portaria-n-343-de-17-de-marco-de-2020-248564376. Acesso em: 22 jul. 2020.

Brasil (2020b). Ministério da Educação. Parecer CNE/CP No: 5/2020, de 28 de abril de 2020. Dispõe sobre a reorganização do Calendário Escolar e da possibilidade de cômputo de atividades não presenciais para fins de cumprimento da carga horária mínima anual, em razão da Pandemia da COVID-19. Disponível em: https://www.semesp.org.br/legislacao/parecer-cne-cp-no-52020. Acesso em: 29 mai. 2020.

Brasil (2020c). Ministério do Estado da Educação. Portaria № 345, de 19 de março de 2020. Disponível em: https://abmes.org.br/arquivos/legislacoes/Portaria-mec-345-2020-03-19.pdf. Acesso em: 19 jun. 2020.

Brasil (2020d). Ministério da Educação. Portaria № 356, de 20 de março de 2020. Disponível em: https://www.in.gov.br/en/web/dou/-/portaria-n-356-de-20-de-marco-de-2020-249090908. Acesso em: 19 jun. 2020.

Brasil (2020e). Ministério da Saúde. Coronavirus - COVID-19. Disponível em: https://coronavirus.saude.gov.br. Acesso em: 6 ago. 2020.

Buarque, C. (2003). Políticas do MEC no âmbito da Educação Pré-Escolar e do Ensino Fundamental. Brasília: FNDE.

Chaves, E. O. C. (1998). O futuro da escola na sociedade da informação. Campinas: Mindware.

Destro, M. R. P. (1999). Educação Continuada: Visão Histórica e Tentativa de Contextualização, São Paulo: Unicamp.

G1 (2020). Dois meses após a suspensão de aulas presenciais, alunos, pais e professores relatam como está a educação durante a pandemia. 2020. Disponível em: https://g1.globo.com/educacao/noticia/2020/05/22/dois-meses-apos-a-suspensao-de-aulaspresenciais-alunos-pais-e-professores-relatam-como-esta-a-educacao-durante-apandemia.ghtml. Acesso em: 22 jul. 2020. 
IPE (2019). INSTITUTO DE PESQUISAS EVOLUTIVAS. Tecnologia na Palma da Mão. Disponível em: http://www.ipe-instituto.org.br/index.php/ciencia-e-tecnologia/1092-tecnologia-na-palmada-mao. Acesso em: 12 set. 2019.

LÉVY, P. (2005). Cibercultura. São Paulo: Editora 34.

Libâneo, J. C. (2004). Organização e gestão da escola: teoria e prática. 5. ed. revista e ampliada. Goiânia: Alternativa.

Martins, R. C. de R. (1999). Formação dos Profissionais do Magistério - PRASEM II, 2. ed. Brasília: FUNDO ESCOLA/MEC.

Nóvoa, A. (2002). Os professores e sua formação. Lisboa: Dom Quixote.

PARANÁ (2020). Conselho Estadual de Educação do Paraná. DELIBERAÇÃO CEE/CP № 01/20, APROVADO EM 31 DE MARÇO DE 2020. Disponível em: http://www.cee.pr.gov.br/arquivos/File/pdf/Deliberacoes/2020/deliberacao_01 20.pdf. Acesso em: 6 ago. 2020.

Pederneiras, M. M. M. et al. (2011). Exame Nacional de Desempenho dos Estudantes na visão de líderes formais. Ensaio: Avaliação e Políticas Públicas em Educação, Rio de Janeiro, 19 (71) 381-400, jun. 2011. Disponível em: https://doi.org/10.1590/S0104-40362011000300009. Acesso em: 22 jul. 2020.

Prado, R. (2003). Profissão Professor: Aprender Sempre. Revista Escola. Edição abril de 2003.

RAMAL, A. C. (2002). Educação na cibercultura: hipertextualidade, leitura, escrita e aprendizagem. Porto Alegre: Artmed.

Recuero, R. C. (2000). A internet e a nova revolução na comunicação mundial. [s. I.], 2000. Disponível em: http://www.raquelrecuero.com/revolucao.htm. Acesso em: 12 set. 2019.

SANTA CATARINA (2020). Conselho Estadual de Educação de Santa Catarina. RESOLUÇÃO CEE/SC № 009, de 19 de março de 2020. Disponível em: http://www.cee.sc.gov.br/index.php/legislacao-downloads/educacao-basica/outrasmodalidades-de-ensino/educacao-basica/educacao-basica-ensino-especial-resolucoes/1812resolucao-2020-009-cee-sc-2. Acesso em: 6 ago. 2020.

Silva, C., Souza, C. \& Carmo, G. (2016). Educação de Jovens e Adultos e Novas Tecnologias da Informação: uma abordagem educacional. Holos, 2, 312-325. DOI: https://doi.org/10.15628/holos.2016.2666.

Souza, W. (2017). "Bolhas sociais": uma crítica ao conceito vulgarizado. [s. I.]. Disponível em: https://acervocriticobr.blogspot.com/2017/03/bolhas-sociais-critica.html. Acesso em: 2 maio 2019. 
Vaz, W. R. (2015). A Evolução da Internet 1.0 a 3.0. [s. I.], 2015. Disponível em: https://www.webartigos.com/artigos/a-evolucao-da-internet-1-0-a-3-0/134074. Acesso em: 2 maio 2019.

\section{COMO CITAR ESTE ARTIGO:}

Baade, J. H., Gabiec, C. E., Carneiro, F. K., Micheluzz, S. C. P., Meyer, P. A. R. (2020). Professores da educação básica no brasil em tempos de Covid-19. Holos. 36(5), 1-17.

\section{SOBRE OS AUTORES}

\section{J. H. BAADE}

Doutor. Docente dos Programas de Mestrado Interdisciplinar em Desenvolvimento e Sociedade e Profissional em Educação da Universidade Alto Vale do Rio do Peixe - UNIARP. E-mail: baadejoel@gmail.com

ORCID ID: https://orcid.org/0000-0001-7353-6648

\section{E. GABIEC}

Mestranda no Programa de Pós-Graduação Profissional em Educação Básica. Universidade Alto Vale do Rio do Peixe - UNIARP. Caçador, Santa Catarina, Brasil. Professora da Rede Municipal de União da Vitória - Escola Municipal Professora Antonieta Montanari. E-mail: crisgabiec@ gmail.com

ORCID ID: https://orcid.org/0000-0003-4586-1261

\section{F. K. CARNEIRO}

Mestranda no Programa de Pós-Graduação Profissional em Educação Básica. Universidade Alto Vale do Rio do Peixe - UNIARP. Caçador, Santa Catarina/Brasil. Professora da Rede Municipal de União da Vitória - Escola Municipal Professora Dille Testi Capriglione. Bolsa parcial provida pela UNIARP e pela Prefeitura de União da Vitória, PR. E-mail: fabicarneiro7@ hotmail.com

ORCID ID: https://orcid.org/0000-0002-0583-7155

\section{S. C. P. MICHELUZZ}

Mestranda do Programa de Mestrado Profissional em Educação Básica (PPGEB) da Universidade Alto Vale do Rio do Peixe (UNIARP). Gestora do Centro de Educação Infantil Mundo Infantil na Rede Municipal de Educação do Município de Massaranduba (2019). Membro do Grupo de Pesquisa em Criatividade, Ecoformação e Transdisciplinaridade (GCET) da UNIARP. E-mail: sandracpmicheluzzi@ gmail.com

ORCID ID: http://orcid.org/0000-0001-8096-1917

\section{P. A. R. MEYER}

Mestre em Desenvolvimento e Sociedade pela Universidade Alto Vale do Rio do Peixe - UNIARP. Docente no Instituto Federal Catarinense, Campus Videira, SC. E-mail: pablomec@gmail.com

ORCID ID: https://orcid.org/0000-0001-9981-0510

Editor(a) Responsável: Francinaide de Lima Silva Nascimento

Pareceristas Ad Hoc: FLÁVIO SANTOS E LENINA SILVA 


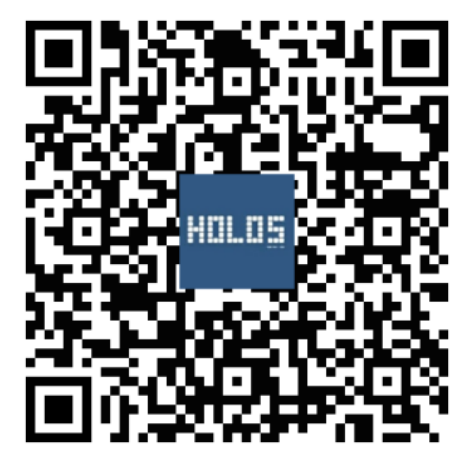

